We also wish to thank Mrs Bonfield, medical secretary, Mr Morris, medical photographer and Mrs Calvert, medical librarian, for their assistance.

\section{References}

Barry, H.C. (1969) Paget's Disease of Bone. E. \& S. Livingstone Ltd, London.

Beeson, P.B. \& McDermott, W. (eds) (1968) Cecil-Loeb Textbook of Medicine, 12th edn, p. 1385. W. B. Saunders, Philadelphia.

Boyd, W. (1970) Textbook of Pathology, 8th edn, p. 1314. Kimpton, London.

Collins, D.H. (1956) Paget's disease of the bone. Lancet, ii, 51.

DAS, S.K. \& Kataria, M.S. (1975a) Corrugated skull in Paget's disease of bone. Modern Geriatrics, 5, 25.
Das, S.K. \& Kataria, M.S. (1975b) British Geriatrics Society Conference (South Eastern Region). Age and Ageing, 4, 63.

Edholm, O.G., Howarth, S. \& McMichael, I. (1945) Heart failure and bone blood flow in osteitis deformans. Clinical Science, 5, 249.

Hodkinson, H.M. (1974) Bone and joint disease in the elderly. Medicine, 25, 1496.

Leading Article (1975) Paget's disease and calcitonin. British Medical Journal, 3, 505.

Newton, F.C. (1924) The mono-osteitic type of Paget's disease (osteitis deformans). Archives of Surgery, 8, 24.

Radiological Atlas-Paget's Disease of Bone, produced as a service to the medical profession by Armour Pharmaceutical Co. Ltd, England.

Sutton, D. (ed.) (1975) A textbook of Radiology, 2nd edn, p. 78. Churchill Livingstone, Edinburgh.

Postgraduate Medical Journal (January 1977) 53, 46-48.

\title{
Myxoedema coma presenting in status epilepticus
}

\author{
K. L. Woods \\ M.B., M.R.C.P.
}

\author{
G. K. T. Holmes \\ M.D., M.R.C.P.
}

Selly Oak Hospital, Birmingham

\begin{abstract}
Summary
A 71-year-old woman with myxoedema coma presenting in status epilepticus is reported. Although this complication of myxoedema coma is considered to be fatal the patient described responded dramatically to treatment and remains in good health.
\end{abstract}

\section{Introduction}

Although still rare, myxoedema with coma has been recognized with increasing frequency in recent years. It is probable that many cases arise as a late consequence of surgical or isotope treatment for thyrotoxicosis. The mortality remains high and prompt diagnosis is vital. In the few instances where fits accompanied coma, a fatal outcome has been almost invariable. The case is reported of a severely hypothyroid patient who presented in status epilepticus and responded well to treatment.

\section{Case report}

A 71-year-old woman was seen by her general practitioner one evening because of confusion and disorientation which had developed over the previous few hours. She was noted to be cold, pale and apparently suffering from acute bronchitis. There was no past history of note. She refused admission and was given $25 \mathrm{mg}$ of chlorpromazine and started on ampicillin. Two hours later she began to have grand mal convulsions and was urgently transferred to hospital.

On arrival she was cyanosed, deeply unconscious and in status epilepticus. Her colour improved after intubation, removal of vomit from the trachea, and assisted ventilation. The fits were controlled with diazepam $10 \mathrm{mg}$ intravenously. Thereafter, adequate spontaneous respiration was maintained.

Examination revealed puffiness of the face with oedema of the eyelids and a dry, coarse skin; the hair was scanty. Her rectal temperature was $31^{\circ} \mathrm{C}$. The blood pressure was initially unrecordable. There were no focal signs in the nervous system; the pupils were small and equal, and the limbs hypotonic with absent reflexes. Throughout both lungs coarse crepitations could be heard. The abdomen was cold to the touch but otherwise unremarkable. 


\section{Investigations}

Sodium $124 \mathrm{mmol} / 1$, potassium $3 \cdot 3 \mathrm{mmol} / \mathrm{l}$, urea $5.0 \mathrm{mmol} / 1$, glucose $3.3 \mathrm{mmol} / 1$, serum aspartate transaminase $321 \mathrm{RFu}$, serum hydroxybutyrate dehydrogenase $840 \mathrm{u}$, amylase 560 Somogyi u, free thyopac index 1.25 (laboratory normal range 4.6 $14 \cdot 0$ ), thyroid stimulating hormone $200 \mu \mathrm{u} / \mathrm{ml}$ (normal range 1-4 $\mu \mathrm{u} / \mathrm{ml}$ ). The ECG was of low voltage but otherwise normal. The chest X-ray showed generalized cardiomegaly and also patchy consolidation of the lungs which became more extensive, receding after the third day. Radiographs of the skull were normal. Thyroid antibodies were demonstrated by the fluorescent antibody technique.

\section{Treatment}

Cautious active re-warming was carried out using an electric blanket at a rate which did not cause a significant fall in blood pressure (Fig. 1). Antibiotic cover was provided from time of admission with ampicillin and flucloxacillin. For the first 3 days $20 \mu \mathrm{g}$ of triiodothyronine and $50 \mathrm{mg}$ of hydrocortisone were given intravenously every $12 \mathrm{hr}$. The patient regained consciousness on the third day and was able to take thyroxine $0.05 \mathrm{mg}$ daily by mouth thereafter. The dose was gradually increased over the next 2 weeks to $0.15 \mathrm{mg}$ daily on which she progressed well enough to be discharged home on the eighteenth day. She has been followed-up for 22 months and remains in excellent health. There has been a dramatic improvement in mental and physical activity. No more fits have occurred.

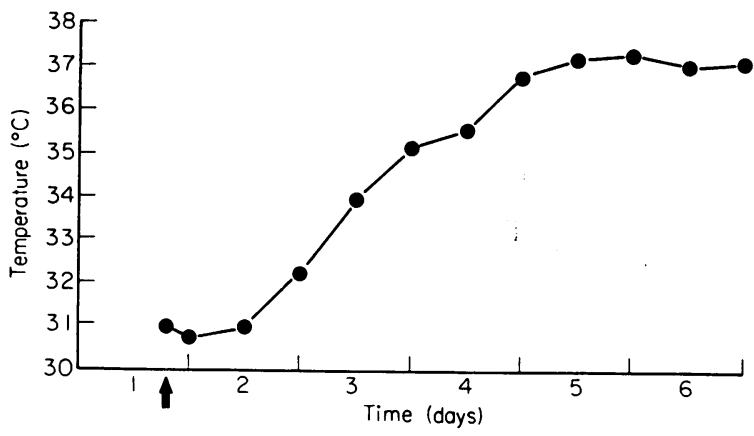

FIG. 1. Temperature chart following admission indicated by the arrow.

\section{Discussion}

The association between hypothyroidism and fits takes two different forms. Late-onset epilepsy has been described in several patients who were later found to be hypothyroid and in whom fits stopped permanently when thyroid hormone was given (Evans, 1960; Jellinek, 1962). By contrast, when convulsions accompany myxoedema coma they are usually pre-terminal. Of nine such cases reported in the English language there were no survivors (Jellinek, 1962; Levin and Daughaday, 1955; Neilson and Ranløv, 1964).

The cause of this seizure activity is unknown. The EEG in hypothyroidism usually shows low voltage alpha activity. When coma intervenes delta and theta waves occur, while in deep coma there may be little electrical activity of any kind (Nieman, 1959). However, even pronounced hypothyroidism can coexist with a normal EEG. It has been postulated that convulsions may be due to cerebral oedema secondary to expansion of the extracellular fluid volume. Inappropriate $\mathrm{ADH}$ secretion is one possible cause of this (Blum, 1972). The serum sodium can fall to quite low levels as in the case described here. Profound hypoxaemia may also play a part in causing convulsions. One hypothyroid patient has been described who had fits during periods of ventricular fibrillation which reverted spontaneously to sinus rhythm (Macauley and Shepherd, 1971). This seems an unlikely mechanism in the present patient, whose fits occurred repeatedly over the course of $1 \mathrm{hr}$ or more before responding to diazepam. Chlorpromazine has been known to precipitate myoedema coma and can lower the convulsive threshold (Mitchell, Surridge and Willison, 1959); this may have been a factor in the present case.

Raised amylase levels are a feature of hypothermia rather than of hypothyroidism (Maclean, Murison and Griffiths, 1973) and focal pancreatic infarction is sometimes found. Elevated serum levels of muscle enzymes, particularly cardiac, have been described in hypothyroid patients without coma (Griffiths, 1965). The sustained high levels suggest diffuse cellular injury rather than focal necrosis as the cause.

Successful therapy of myxoedema coma requires prompt attention to several points. First, hypothermia should be treated with active re-warming at a rate which does not cause the blood pressure to fall. Secondly, intravenous triiodothyronine provides the fastest possible correction of hypothyroidism. Thirdly, antibiotic cover should be provided as without it bronchopneumonia almost invariably develops. Fourthly, steroid cover is advisable in view of the small percentage of patients whose hypothyroid state is due to pituitary disease. Finally, it may be necessary to use artificial ventilation if spontaneous respiration becomes inadequate.

\section{Acknowledgments}

We wish to thank Dr R. Cockel for permission to report this case and for his help in preparing the manuscript.

\section{References}

Blum, M. (1972) Myxedema coma. American Journal of the Medical Sciences, 264, 432. 
Evans, E.C. (1960) Neurological complications of myxedema convulsions. Annals of Internal Medicine, 52, 434.

GRIFfiths, P.D. (1965) Serum enzymes in diseases of the thyroid gland. Journal of Clinical Pathology, 18, 660.

JeLLiNeK, E.H. (1962) Fits, faints, coma and dementia in myxoedema. Lancet, ii, 1010.

Levin, M.E. \& Daughaday, W.H. (1955) Fatal coma due to myxedema. American Journal of Medicine, 18, 1017.

Macauley, M.B. \& Shepherd, R.J. (1971) Syncope in myxoedema due to transient ventricular fibrillation. Postgraduate Medical Journal, 47, 361.
Maclean, D., Murison, J. \& Griffiths, P.D. (1973) Acute pancreatitis and diabetic keto-acidosis in accidental hypothermia and hypothermic myxoedema. British Medical Journal, 4, 757.

Mitchell, J.R.A., Surridge, D.H.C. \& Willison, R.G. (1959) Hypothermia after chlorpromazine in myxoedematous psychosis. British Medical Journal, 2, 932.

Neilsen, P.E. \& Ranløv, P. (1964) Myxoedema coma Two case reports and a review. Acta endocrinologica, 45, 353.

Nieman, E.A. (1959) The electroencephalogram in myxoedema coma. British Medical Journal, 1, 1204.

\title{
Sarcoma complicating therapy with cyclophosphamide
}

\author{
J. S. MARKS \\ M.A., B.M., B.Ch., M.R.C.P. \\ C. L. SCHOLTZ* \\ M.B., B.S., F.R.C.P.A. \\ Rheumatism Research Centre, Manchester Royal Infirmary, and \\ *University Department of Pathology, Manchester
}

\begin{abstract}
Summary
A patient is described who developed a poorly differentiated sarcoma after cyclophosphamide was used to treat his rheumatoid arthritis. This case emphasizes the importance of considering neoplastic disease as a potential hazard associated with the use of immunosuppressive drugs.
\end{abstract}

\section{Introduction}

The development of neoplasms after immunosuppressive therapy has been reported previously (Doll and Kinlen, 1970). The great majority have been either of the lymphoreticular type, frequently involving the central nervous system, or cancers involving superficial epithelium. The occurrence of a poorly differentiated sarcoma in a patient during treatment with cyclophosphamide is reported.

\section{Case history}

The patient, a janitor aged 62 , initially presented in August 1969 with painful hands and feet. A diagnosis of seropositive rheumatoid arthritis was made and treated with chloroquine phosphate 250 mg daily for 1 year. In November 1972 there was an exacerbation of his joint symptoms and he was started on prednisolone $15 \mathrm{mg}$ daily but continuing disease activity necessitated the addition of cyclophosphamide $50 \mathrm{mg}$ twice daily in February 1975.

Correspondence: Dr J. S. Marks, Rheumatism Research Centre, Manchester Royal Infirmary, Manchester M13 9WL.
In August 1975 he was admitted to the Manchester Royal Infirmary. There was a 2-month history of progressive exertional dyspnoea and $10 \mathrm{~kg}$ weight loss. Examination revealed a hypercorticoid cyanosed? patient with finger clubbing, a left pleural effusion and chronic rheumatoid joint changes. Investigations showed a haemoglobin of $13.6 \mathrm{~g} / 100 \mathrm{ml}$; white cell count of 6,900 with a normal differential; an ESR of $40 \mathrm{~mm}$ in $1 \mathrm{hr}$ (Westergren). Routine biochemical tests were all normal. A chest X-ray film confirmed the presence of a left pleural effusion. Cytological examination of the blood-stained pleural aspirate showed it to contain neoplastic cells and needle biopsy of the pleura revealed infiltration with anaplastic tumour cells.

The patient's clinical condition deteriorated and he died 1 week later. At post-mortem the pleura was covered with a grey nodular tumour but sections of the bronchi failed to reveal any primary tumour. Histological examination of the tumour confirmed it to be a poorly differentiated sarcoma.

\section{Discussion}

The alkylating agent cyclophosphamide appears to be an effective therapeutic agent in certain connective tissue disorders including rheumatoid arthritis (Cooperating Clinics Committee, 1970). The adverse side effects of this drug constitute a major limitation to its widespread clinical use and in particular there is a possible risk of malignant transformation. A full 